\title{
Sublingual Ranula Cases and Our Surgical Approach
}

\author{
mehmet erkan kaplama ${ }^{1}$, mesut tozar ${ }^{2}$, kamile nur tozar ${ }^{3}$, and Burak Erden ${ }^{4}$ \\ ${ }^{1}$ Affiliation not available \\ ${ }^{2}$ Adiyaman Universitesi Egitim ve Arastirma Hastanesi \\ ${ }^{3}$ Adryaman University Faculty of Dentistry \\ ${ }^{4}$ Mersin Şehir Eğitim ve Araştırma Hastanesi
}

December 4, 2020

\begin{abstract}
Objective: In ranula etiology, trauma in submandibular and sublingual glands and trauma in secretory ducts have role. There are many different treatment strategies ranging from drainage to ekcision of sublingual gland with ranula. Aim of this study is evaluation of the effects of usage of surgicel in ranula surgery instead of marsupialization with gauze ped. Materials and methods: We included 26 patients to our study who had sublingual ranula surgery and fulfil study criteria Results: Significant differences were not determined according to age,sex, anesthesia type and ranula size. Infection signs were not seen in postoperative one week control of patients. In six months controls, oral base wound was healed totally and there were no relapse cases. Conclusions: In result of this study, We showed that using of surgicel with marsupialization is an effective therapeutic method and it decreases relaps rates in ranula patients.
\end{abstract}

\section{Hosted file}

manuscript.pdf available at https://authorea.com/users/375823/articles/497055-sublingualranula-cases-and-our-surgical-approach 


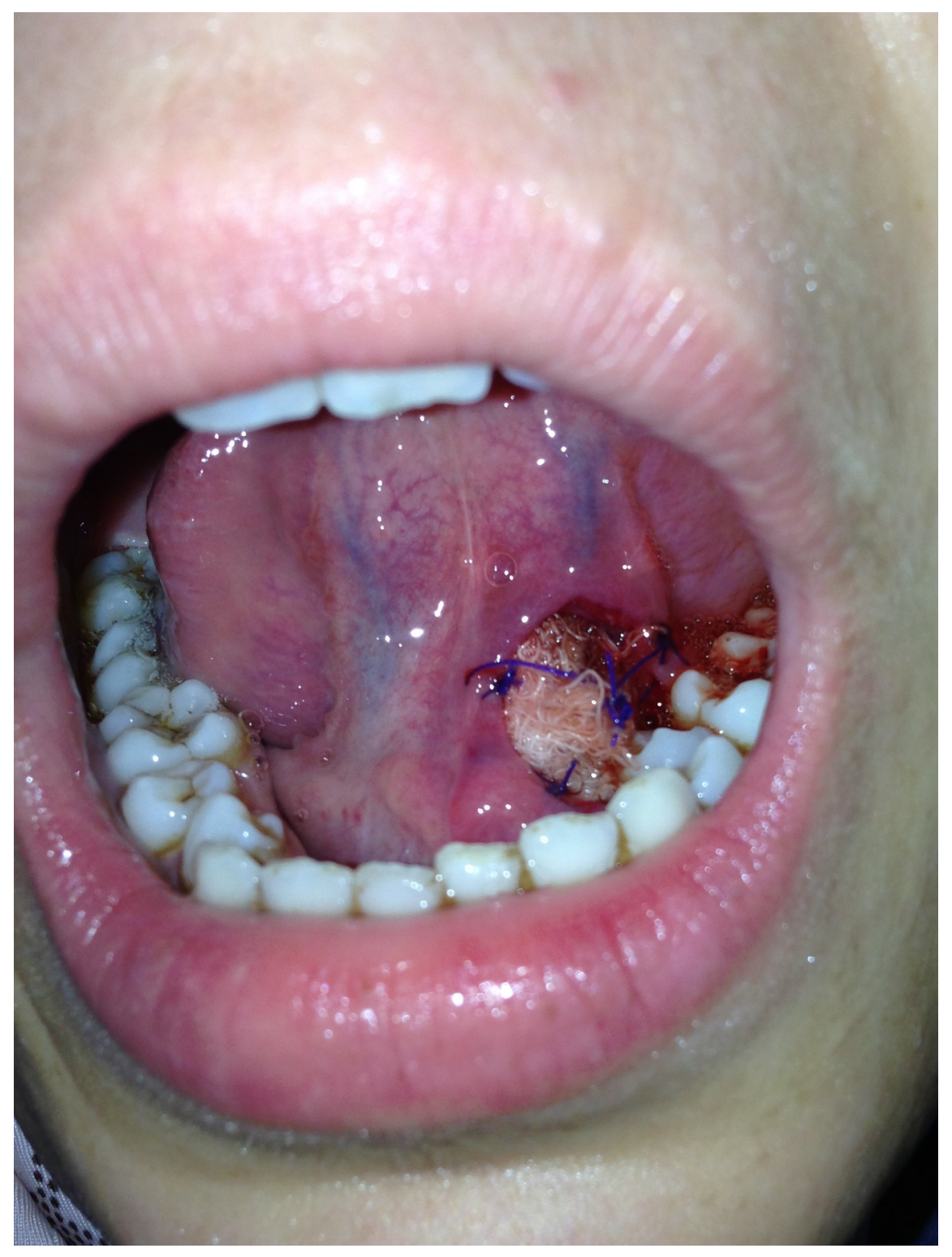




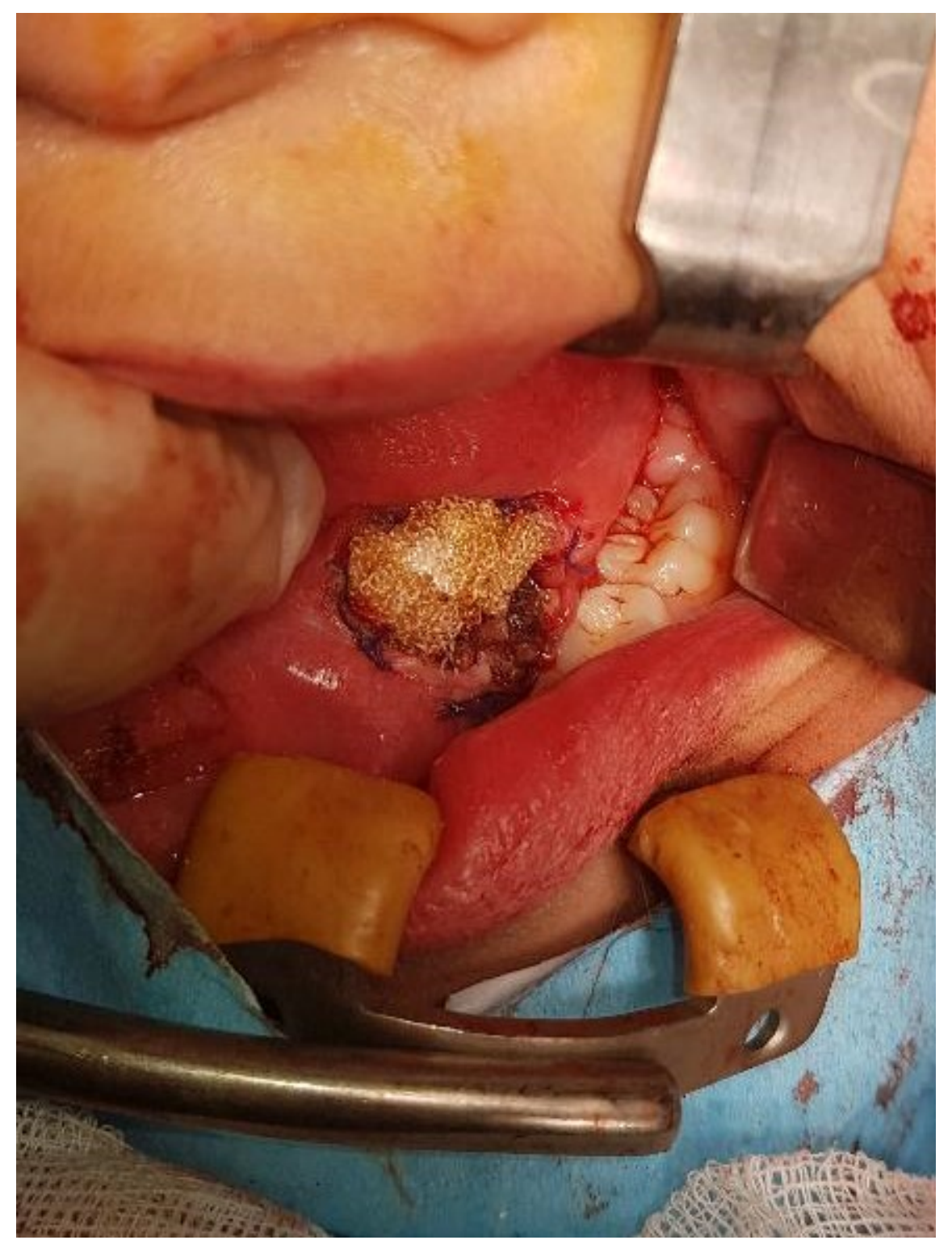




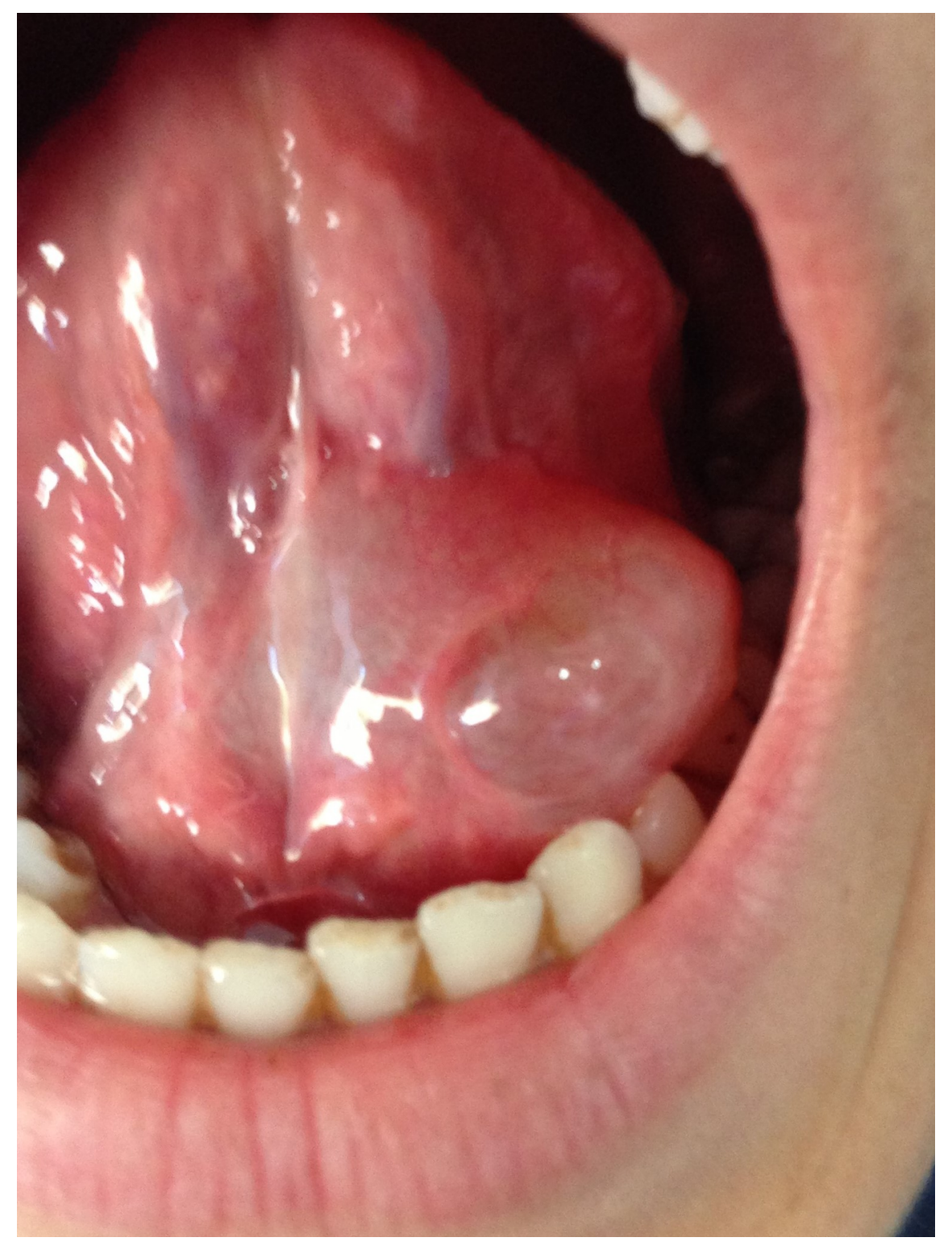




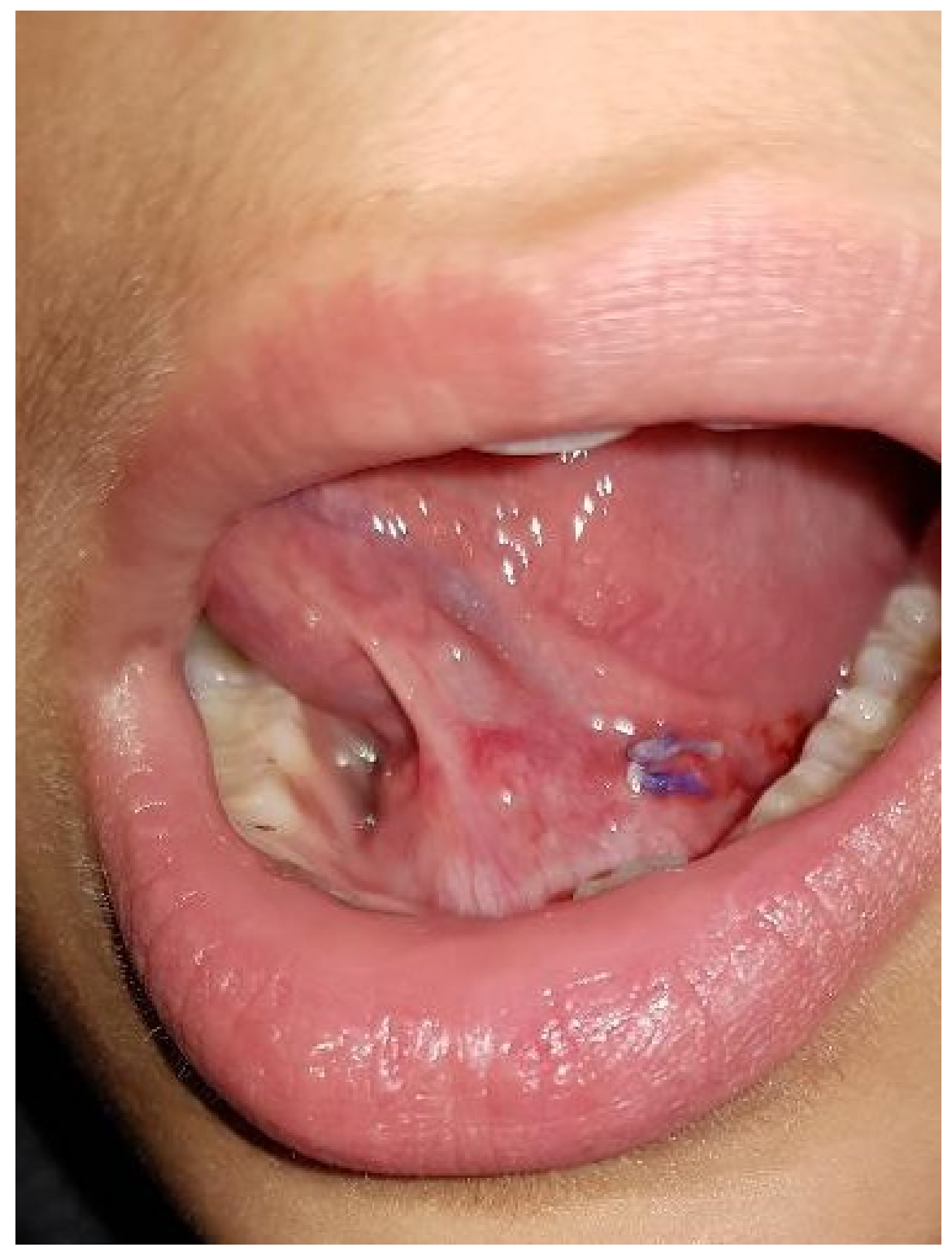

